\title{
Did Brexit change Asset Co-Movements?
}

\author{
Shrabani Saha \\ Lincoln International Business School, \\ University of Lincoln, UK \\ Anindya Sen \\ Department of Accounting and Finance \\ University of Otago, New Zealand \\ Christine Smith-Han \\ Forsyth Barr, New Zealand \\ and \\ Dennis Wesselbaum \\ Department of Economics \\ University of Otago, New Zealand
}

\begin{abstract}
This article examines the impact of the Brexit referendum on the risk structure of financial asset prices. Co-movements are analysed using daily price returns of major stock and bond indices as well as commodities and exchange rates from June 2014 to June 2018. We employ a multivariate GARCH model to study the dynamics of the conditional correlation matrix of asset returns. We find that the conditional variances and correlations of assets spike on and after the Brexit referendum and then quickly revert to normal levels, suggesting that the effect of the referendum was transient rather than structural. Our findings are of interest to investors as co-movements of financial assets can significantly impact financial portfolios and hedging strategies.
\end{abstract}

Keywords: Brexit, Dynamic Conditional Correlations, Financial Markets.

JEL Codes: G14, G15, G32.

\section{Data Availability}

The financial data used in this paper is proprietary and therefore cannot be shared. 


\section{Did Brexit change Asset Co-Movements?}

\section{Introduction}

"The UK economy has entered a period of adjustment following the EU referendum. The likelihood that some UK-specific risks to financial stability could materialise remains elevated." Bank of England, Financial Stability Report November 2016.

On June 23, 2016 a referendum was held about the relationship between the United Kingdom and the European Union. A majority of 51.9 percent of the UK population voted to leave and the UK officially started the withdrawal process on March 29, 2017, by triggering article 50 of the Lisbon Treaty. This outcome of the referendum was surprising (Becker et al., 2017) and the Pound Sterling and stock markets plunged in response.

At the point of triggering article 50, the UK was set to officially leave the EU on March 29, 2019 with a transition period ending on December 31, 2020. The negotiations about possible exit scenarios (e.g. Norway or Canada options, Swiss-Model, or Customs-Union just to name a few) created significant uncertainty for financial markets and triggered widespread concern on the future of the financial sector, both in the UK and abroad (Howrah and Quaglia, 2018). The United Kingdom is a key player in the international financial system and is the most central and important node in the international financial network behind the United States (Korniyenko et al., 2018). Given this central role, adjustments after Brexit and the uncertainty surrounding it are likely to have important effects on asset pricing and risk management.

Along this line, correlations are central to finance theory and modelling. Whether it is optimal portfolio allocation (e.g. Capital Asset Pricing Model), pricing (e.g. Arbitrage 
Pricing Theory), financial stability, or risk management, time-varying volatilities and correlations matter (Embrechts et al., 2002 and Andersen et al., 2007). For example, studies by Krishnan et al. (2009), Driessen et al. (2012), and Buss et al. (2017) study the pricing of variance and correlation risk and Branger et al. (2018) study the effect of stochastic covariances on the behaviour of international investors.

In this paper, we study the short-term effect of the Brexit referendum on the unconditional and conditional correlations of different British assets (stocks, bonds, commodities, and currencies) with assets of UK's main trading partners (Germany, France, US, and Japan). In order to capture potential anticipation effects, we construct a symmetric sample around the Brexit referendum date of about 520 days. In a first step, we present the unconditional correlation matrix before and after the Brexit referendum. In a second step, we employ a multivariate generalized autoregressive conditional heteroscedasticity model, the Dynamic Conditional Correlation model (DCC, for short) proposed by Engle (1999). This model allows us to study the conditional variance and the conditional correlations among the various assets. This will give us insights into whether the Brexit referendum affected the underlying riskiness of assets in the short run.

Our key findings can be summarized as follows. First, we find that the unconditional correlation matrix has changed sizably after the Brexit referendum. The unconditional co-movement of all types of assets (stocks, bonds, and currencies) in the UK with various assets (stocks, bonds, commodities, and currencies) across important trade partners has changed. Second, and most important, our results show that Brexit generated a large spike in the conditional second moments of all variables. Risk (conditional variance) and correlations reacted strongly to the Brexit referendum outcome. While this spike was only temporary for riskiness, it had persistent effects 
on the conditional correlation of the British stock market index with other assets. We conclude that the Brexit referendum outcome did affect the underling riskiness and the correlation between assets for the stock market, i.e. UK companies, but not for the government. These insights are important for financial stability, risk management, asset pricing within and outside the UK. They offer relevant insights for policy makers, central bankers, and investors.

\section{Literature Review}

To the best of our knowledge, this is the first paper investigating the effect of the Brexit referendum on the riskiness and the (un)conditional correlation structure of various asset types. However, the Brexit event has generated a growing literature of papers dealing with the financial market implications.

Smales (2017) uses the 30-day FTSE 100 implied volatility index (IVI) to study the effects of political uncertainty regarding the EU referendum. He finds that the uncertainty matters close to the polling date.

Papers such as Belke et al. (2018) investigate the effect of policy uncertainty on stock returns and other financial market variables. Caporale et al. (2018) investigate whether Brexit affected the (implied) volatility of the FTSE and the British Pound using a long-memory method. Kenourgios et al. (2020) study the links between Brexit and subsectors of the EU-28 and UK stock indices. The find that, surprisingly, only a few subsectors have been affected (e.g. negative effect on financial sector but positive effect on basic materials and health care sectors). Kara et al. (2020) study the

Clark and Amen (2017) study the link between Brexit poll results and the GBP-USD FX spot rates from January to June 2016. They apply an option pricing model and find 
significant tail mass probability for the Brexit leave vote. The model implies a devaluation of the British pound. Belke and Ptok (2018) relatedly study the effect of Brexit on exports to Belgium, Germany, France, Italy, and the Netherlands. They find that uncertainty does not matter for exports from the UK to these European countries, but uncertainty matters for exports from these countries to the UK.

The closest paper to ours is by $\mathrm{Li}$ (2020). The paper uses a six-dimensional VAR-BEKK model and provides volatility decompositions into direct and indirect spillovers for the effect of Brexit on stock markets (UK, Germany, France, Ireland, Italy, and Poland). The findings show that the UK is a net transmitter of volatility towards the stock market, but its impact has decreased this the EU referendum. Our paper is different in our research question and our research methodology as we focus on stochastic second moments and a full description of the conditional variance-covariance matrix.

\section{Method}

The Dynamic Conditional Correlation (DCC) model developed by Engle and Sheppard (2001) estimates and forecasts the variance-covariance matrix of a vectorautoregressive (VAR) process using a more parsimonious method than standard multivariate GARCH models. The key idea behind the method is to decompose the variance-covariance matrix of the process into a diagonal matrix of variances and a matrix of correlations, then estimate the relevant parameters separately. The DCC model is particularly useful in the context of our article, since our interest lies primarily in the analysis of the time-varying correlations between a number of economic time series, rather than obtaining the variance-covariance matrix. In this section, we will briefly outline the concept and estimation procedure behind the VARDCC model. 
Multivariate GARCH models are defined using the two equations:

$$
\begin{aligned}
& Y_{t}=\mu_{t}+a_{t}, \\
& a_{t}=H_{t}^{1 / 2} z_{t},
\end{aligned}
$$

where

$\mathrm{Y}_{\mathrm{t}}: \mathrm{n} \times 1$ vector of random variables at time $\mathrm{t}$.

at : $\mathrm{n} \times 1$ vector of mean-corrected variables at time t, i.e., $\mathrm{E}[\mathrm{at}]=\mathrm{o}, \operatorname{Cov}[\mathrm{at}]=\mathrm{H}_{\mathrm{t}}$.

$\mu_{\mathrm{t}}: \mathrm{n} \times 1$ vector of the expected value of $\mathrm{Y}_{\mathrm{t}}$ In a VAR model, this is modelled as a multivariate time series with $\mathrm{p}$ lags.

$\mathrm{H}_{t}$ : $\mathrm{n} \times \mathrm{n}$ matrix of conditional variances of at at time t. This is a positive-definite symmetric matrix.

$\mathrm{H}^{1 / 2}$ : The "square root" of the matrix $\mathrm{H}_{\mathrm{t}}$ obtained by diagonalization of the matrix. $\mathrm{Zt}: \mathrm{n} \times 1$ vector of iid errors such that $\mathrm{E}[\mathrm{zt}]=\mathrm{O}$ and $\mathrm{E}\left[\mathrm{ztzt}^{\prime}\right]=$ Identity matrix. In addition, we assume that $\mathrm{zt}$ follows a multivariate normal distribution. It is possible to estimate the conditional variance matrices $\mathrm{H}_{\mathrm{t}}$ directly, but the number of parameters increases rapidly and the estimation procedure becomes computationally expensive.

The DCC reduces the computational cost by modelling the conditional variances and correlations separately. This technique is also especially useful when estimating the time-varying matrix of correlations is of primary interest.

The first step is to decompose the variance-covariance matrix as

$$
H_{t}=D_{t} R_{t} D_{t},
$$


where

$\mathrm{D}_{\mathrm{t}}=\operatorname{diag}\left(\sqrt{h_{1 t}}, \ldots, \sqrt{h_{n t}}\right)$ is the diagonal matrix of conditional standard deviations and $R_{t}$ is the conditional correlation matrix at time $t$.

The DCC model assumes that the matrix $R_{t}$ varies with time and estimates its values. The conditional variances, $\left\{\mathrm{h}_{\mathrm{it}}\right\}$, are estimated for each variable using univariate GARCH models (where i ranges from 1 to $\mathrm{n}$ )

$$
h_{i t}=\alpha_{i 0}+\sum_{q=1}^{Q_{i}} \alpha_{i q} a_{i, t-q}^{2}+\sum_{p=1}^{P_{i}} \beta_{i p} h_{i, t-p}
$$

In general, each univariate model to determine a conditional variance can have a different order. To estimate the correlation matrix $\mathrm{R}_{\mathrm{t}}$, we first normalize the vector of variables at to get a new vector of variables $\epsilon_{t}$, where

$$
\epsilon_{t}=D_{t}^{-1} a_{t} \sim N\left(0, R_{t}\right)
$$

Since $\mathrm{R}_{\mathrm{t}}$ is a positive definite, symmetric matrix where the diagonal elements are 1 are all elements lie between 1 and -1, we ensure this by further decomposing $\mathrm{R}_{\mathrm{t}}$ as follows.

$$
\begin{gathered}
R_{t}=Q_{t}^{*-1} Q_{t} Q_{t}^{*-1} \\
Q_{t}=\left(1-\sum_{m=1}^{M} \alpha_{m}-\sum_{k=1}^{K} \beta_{k}\right) \bar{Q}+\sum_{m=1}^{M} \alpha_{m} \epsilon_{t-m} \epsilon_{t-m}^{\prime}+\sum_{k=1}^{K} \beta_{k} Q_{t-k}
\end{gathered}
$$

where $\bar{Q}=\mathrm{E}\left[\epsilon_{t} \epsilon_{t}{ }^{\prime}\right]$ and $\mathrm{Q}^{*}{ }^{*}=\operatorname{diag}\left(\sqrt{q_{11, t}}, \ldots, \sqrt{q_{n n, t}}\right)$ is used to scale the elements of $\mathrm{Q}_{\mathrm{t}}$ to ensure that they lie between $\mathrm{O}$ and 1 . Now the elements of $\bar{Q}$ can be estimated simply by using the sample mean, namely:

$$
\hat{\bar{Q}}=\frac{1}{T} \sum_{t=1}^{T} \epsilon_{t} \epsilon_{t}^{\prime}
$$


Thus, the problem of estimating the correlation matrix, $\mathrm{R}_{\mathrm{t}}$, reduces to estimating the parameters $\left\{\alpha_{m}\right\}$ and $\left\{\beta_{k}\right\}$. This is done by maximum likelihood estimation as outlined below.

To avoid notation overload, we use $\phi$ to denote the set of all parameters involved in the estimation of the conditional variances $\left\{\mathrm{h}_{\mathrm{it}}\right\}$ and $\psi$ to denote the set of parameters $\left\{\alpha \_1, \ldots, \alpha_{M}, \beta_{-} 1, \ldots, \beta_{K}\right\}$ involved in the estimation of the correlation matrix $\mathrm{R}_{\mathrm{t}}$. With this notation, the likelihood function depends on the parameter set $\phi$ and $\psi$ and can be written as

$$
L(\phi, \psi)=\prod_{t=1}^{T} \frac{1}{(2 \pi)^{\frac{n}{2}}\left|H_{t}\right|^{\frac{1}{2}}} \exp \left\{-\left(a_{t}^{\prime} H_{t}^{-1} a_{t}\right)\right\}
$$

Direct estimation of all the parameters is difficult and computationally expensive among other things; it involves the inversion of the $\mathrm{n} \times \mathrm{n}$ matrix $\mathrm{H}_{\mathrm{t}}$ which is itself a complicated function of the parameter set.

However, we simplify this using a two-step estimation procedure described below. The first step involves ignoring the correlation structure and estimating the parameter set $\phi-$ in other words, we assume that the correlation matrix is the identity in the likelihood function. This assumption allows us to express the likelihood function as a function of only the parameter set $\phi$ - in fact, after some algebra, the log-likelihood function becomes:

$$
\ln \left(L_{1}(\phi)\right)=\sum_{i=1}^{n}\left\{-\left(\frac{1}{2}\right) \sum_{t=1}^{T}\left[\ln \left(h_{i t}\right)+\left(\frac{a_{i t}^{2}}{h_{i t}}\right)\right]+\text { constant }\right\}
$$

Note that this log-likelihood function is the sum of the log-likelihood estimators for the GARCH models to estimate the conditional variances $\{$ hit $\}$ and depends only on 
the parameter set $\phi$. In other words, by maximizing this function, we are essentially doing univariate GARCH estimation for each $h_{i t}$. Maximizing the likelihood function $\mathrm{L}_{1}$ above gives us estimators $\hat{\phi}$ for the parameters $\phi$.

Substitution of these values ensures that the original likelihood function now depends only on the parameters $\psi$ - in fact, once we plug in the values of $\hat{\phi}$ and exclude all constant terms, we merely need to maximize the function

$$
\ln \left(L_{2}(\psi)\right)=-\frac{1}{2} \sum_{t=1}^{T}\left\{\ln \left(\left|R_{t}\right|\right)+\epsilon_{t}^{\prime} R_{t}^{-1} \epsilon_{t}\right\} .
$$

This gives us estimators $\hat{\psi}$ for the parameters $\psi$ which can then be used to estimate the correlation matrix $\mathrm{R}_{\mathrm{t}}$.

Engle and Sheppard (2001) show that this technique yields consistent and asymptotically normal estimators of the correlation matrix. Jondeau (2005) compares the two-step procedure with a direct maximum likelihood estimation and finds that they yield very similar results.

\section{Data and Model Choice}

This paper uses data on various financial time series. The data set is symmetric around the Brexit referendum on June 23, 2016. We use 1045 observations (523 before, 521 after the referendum) on a daily frequency. We use data on exchange rates, commodities, bonds, and equities. Our choice of variables reflects the UK's major trading partners.

For exchange rates, we use British Pound Sterling to Euro, US Dollar, Swiss Franc, and Japanese Yen. Commodities include the price of Corn (No. 2 Yellow, US\$ per Bushel), Copper (LME, US Dollar per Tonne), Natural Gas, Oil (Crude Oil, WTI Spot, US Dollar 
per Barrel), and Gold. Further, we use the 10-year Treasury bond yields for Japan, the USA, France, Germany, and the United Kingdom. Finally, we use the following stock indices: FTSE 100 (UK), Dax 30 (Germany), CAC 40 (France), and Dow Jones Industrial (USA).

We then log all variables except the exchange rates and Treasury bond yields. The data is first-differenced to ensure stationarity (as required by our econometric model).

To ensure that our data exhibits dynamic conditional correlations, we run the test proposed by Engle and Sheppard (2001). They develop a test on constant correlation where the residuals of the univariate GARCH processes are standardized. Then, while jointly standardizing by the symmetric square root decomposition of the correlation matrix, the correlation matrix of these standardized residuals is estimated. The hypothesis is that if correlations would truly be constant, the residuals would be i.i.d. with an identity matrix as covariance matrix. When we run this test on our data set, we find that the hypothesis of constant is rejected (with a p-value of 0.07). In addition, when the run a VAR- Constant Correlation model, the LM test shows presence of GARCH in the residuals.

Finally, for estimating the mean, we find that 2 lags are optimal (AIC criterion). Further, the VAR-DCC model with a DCC: $\mathrm{P}=2, \mathrm{Q}=5$, an $\mathrm{ARCH} \mathrm{P}=5$, and a GARCH $Q=1$ structure yields the best fit to the data.

5. Results 
This section presents our empirical results. The first step examines the unconditional correlations of various daily price returns of assets. In the second step, we present the time-varying conditional variance and correlations of asset returns.

\subsection{Unconditional Correlation}

Unconditional correlation of asset returns is studied using a heat map as a graphical representation of the unconditional correlation matrix. Dark colours indicate a negative correlation. Figure 1 presents the unconditional correlation structure in our sample before the Brexit referendum and figure 2 presents the results for the sample after the Brexit referendum.

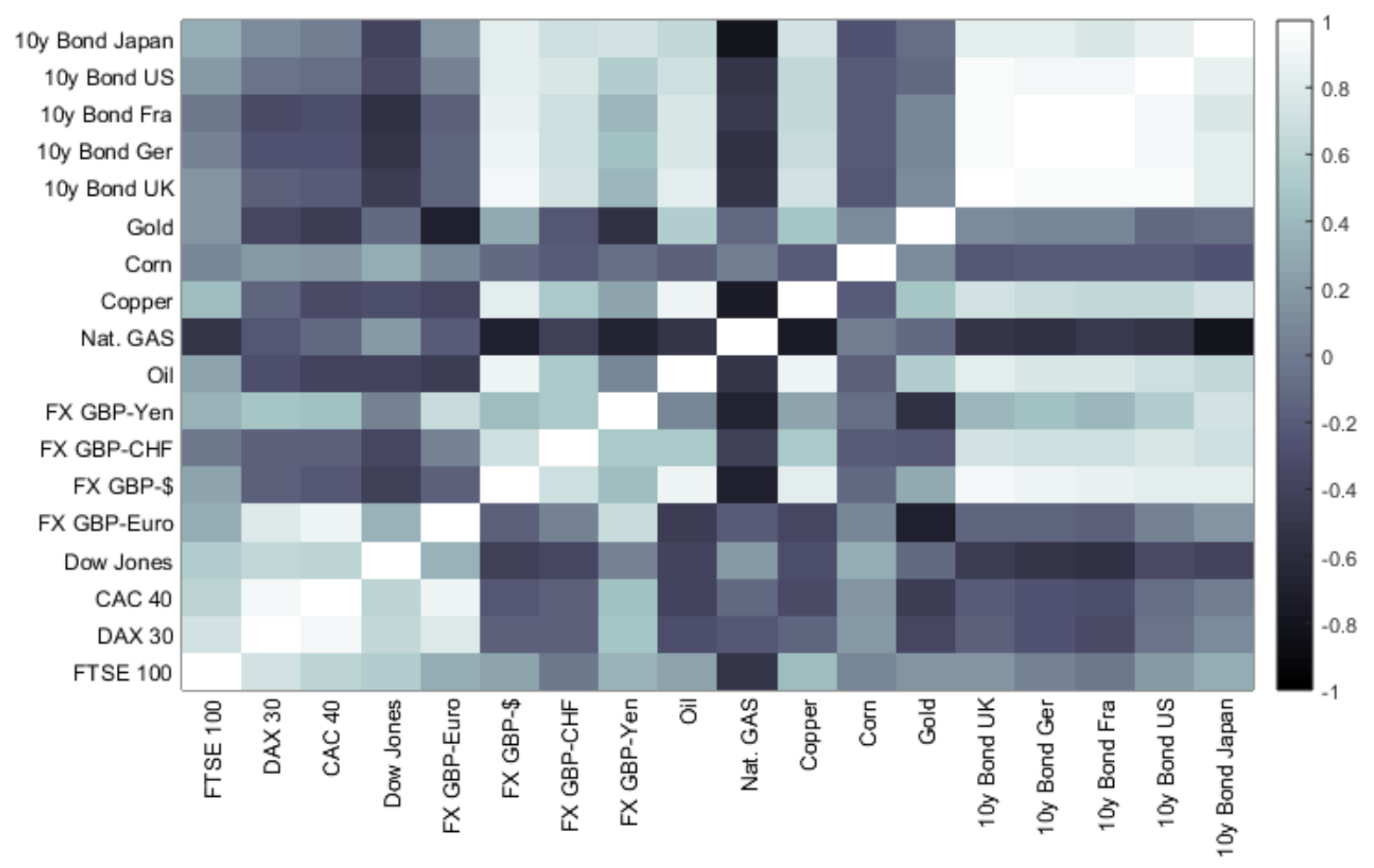

Figure 1: Unconditional Correlation Heat Map, before Brexit referendum.

The unconditional correlation of the UK stock market (measured by the FTSE100) has changed dramatically for the other stock markets (Dax 30, CAC 40, and the Dow 
Jones): while the correlation was slightly positive before the Brexit referendum, there was an almost on-to-one, positive correlation after the referendum. For currencies and the FTSE100 we find a slightly more positive correlation with the Yen, the Swiss Franc, and the US Dollar. Interestingly, the correlation changed from mildly positive to strongly negative with the Euro. This is important particularly for international investors. The correlation of the FTSE100 with bonds has become slightly more positive after the referendum. Finally, the correlation of the FTSE10o with commodities has become more strongly positive, in particular for natural gas.

The correlation of 10 year UK Treasury Bonds with the 10 year bonds from Japan, the US, France, and Germany has become slightly less positive. Interestingly, the correlation of 10 year UK Treasury bonds with the stock market indices from the other countries (Dax 30, CAC 40, and the Dow Jones) has shifted from a negative correlation to a positive one after the referendum. We also see that the negative correlation of UK Treasury bonds with natural gas shifted from negative to positive after the referendum. The correlation with currencies has decreased and after the referendum is less positive. For the GBP-Euro exchange rate, the interesting observation is that it comoves negatively with the stock market indices, while it used to co-move positively.

Overall, we find sizable changes in the unconditional co-movement of all types of assets (stocks, bonds, and currencies) in the UK with various assets (stocks, bonds, commodities, and currencies) across important trade partners. This suggests that the Brexit referendum, expectations about the Brexit, and uncertainty jointly affected the co-movement of assets in the short-run. Obviously, there will be other factors that can affect the unconditional correlation between these assets, including, for example, US policy uncertainty or the US-Chinese trade war. However, Brexit has been the "most 
significant political even in the first half of 2016 [...]" (Belke et al., 2018) and we therefore expect that most of the observed changes can be attributed to Brexit.

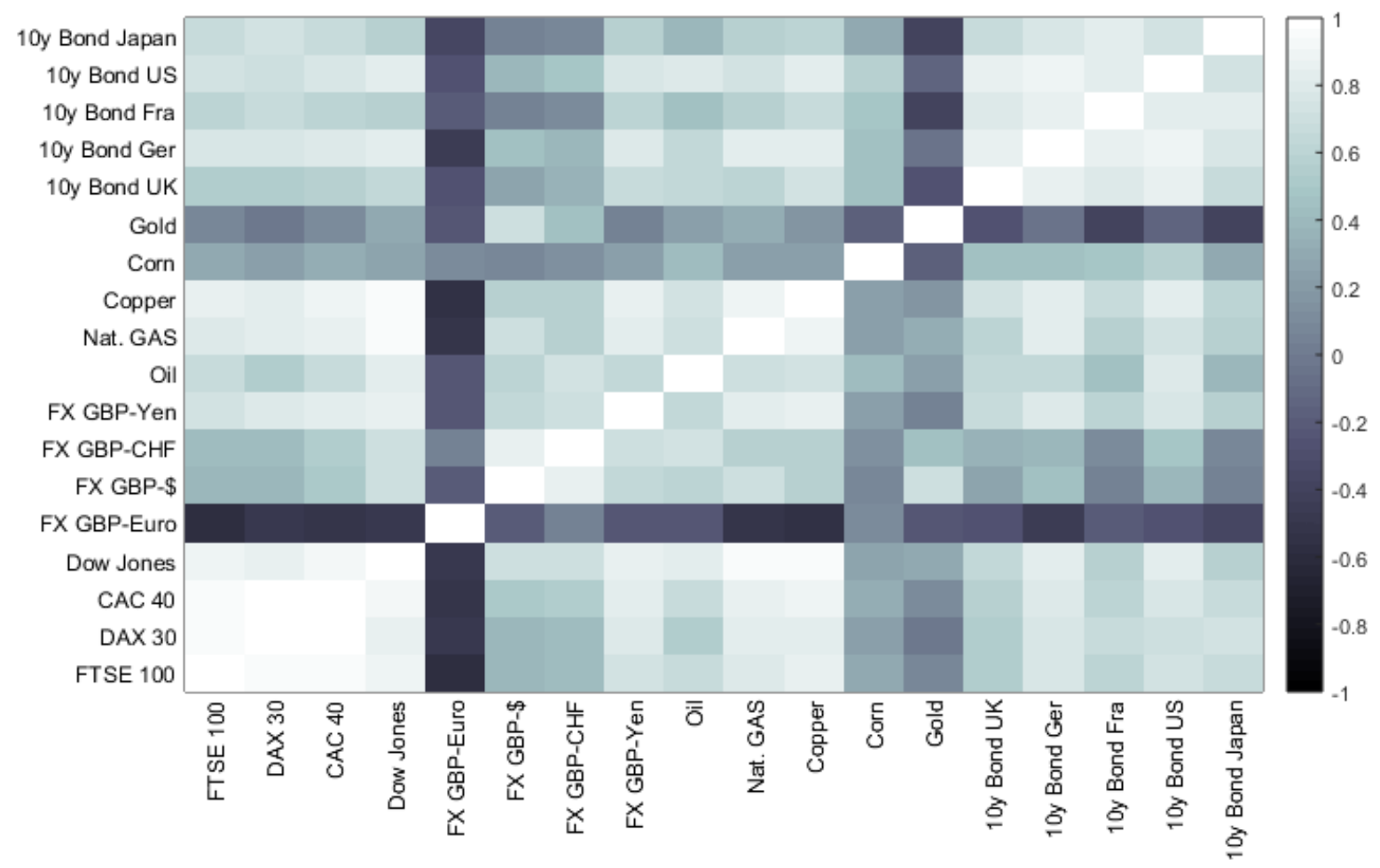

Figure 2: Unconditional Correlation Heat Map, after Brexit referendum.

\subsection{Conditional Variances and Correlations}

The previous section provided suggestive evidence that the Brexit referendum had an effect on the unconditional correlation of various assets. In this section, we want to investigate the time-varying conditional variances and the time-varying conditional correlations.

Figure 3 and 4 present the conditional variances of all the variables in our data set over the entire sample period (before and after Brexit referendum). The first red line in each 
graph shows the date of the Brexit referendum and the second red line shows the day article 50 was officially triggered.
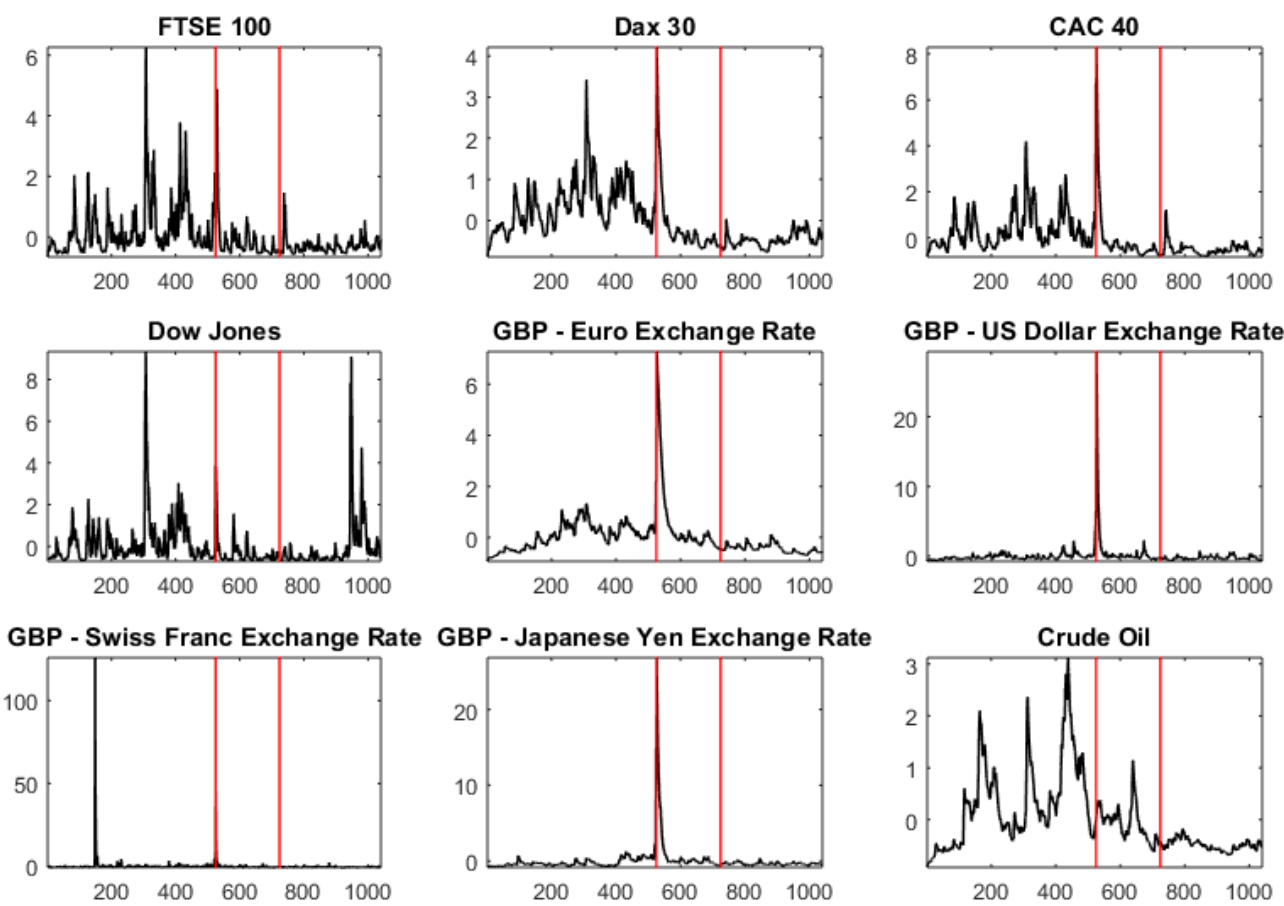

Figure 3: Conditional Variances. First vertical red line is referendum date (June 23, 2016), second red line is date article 50 was triggered (March 29, 2017).

The take-away is that Brexit created a large spike in the conditional variance or the underlying riskiness of all variables. However, more interesting is the observation that this increase in the conditional variance (or risk) was only temporary and disappeared after a couple of days. In fact, when we compare the conditional variance before and after the referendum, we even observe less volatility in some variables such as the FTSE100, Dax 30, CAC40, the Dow Jones, Crude Oil, Gold, and Treasury bonds. While we acknowledge that the further we move away from the Brexit referendum date, other unobservable events are more likely to affect the conditional variance, undoubtedly the outcome of the Brexit referendum increased risk in the market (for all asset 
classes) temporarily. Further, the day of triggering article 50 had only small effects on the riskiness of our variables. Not surprisingly, as triggering article 50 was anticipated and no "news" were revealed about the Brexit process.
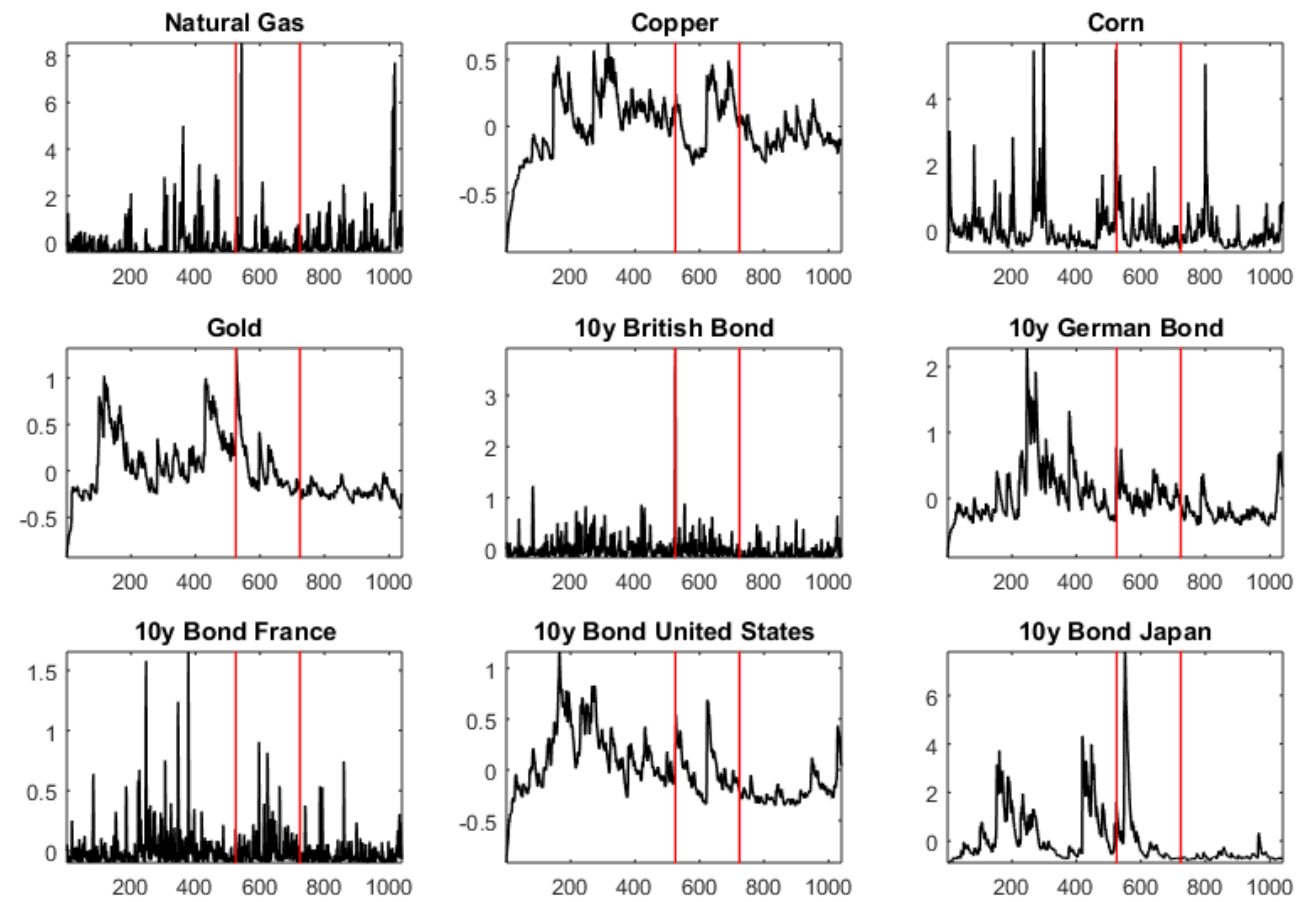

Figure 4: Conditional Variances. First vertical red line is referendum date (June 23, 2016), second red line is date article 50 was triggered (March 29, 2017).

Given the role played by financial market in the UK, it should not be surprising to see spikes also in riskiness in other countries. This opens the question what happened to the conditional correlations after the Brexit referendum. Understanding these conditional correlations is important for risk management, financial stability, and asset pricing models. These conditional correlations (for the FTSE100 and the 10 year UK Treasury Bond) are presented in figures 5 and 6 . As before, the red lines indicate the day of the Brexit referendum and the day article 50 was triggered. 

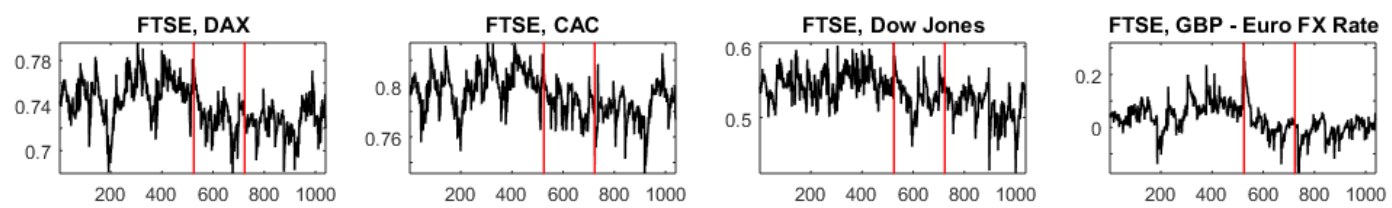

FTSE, GBP - US Dollar FX Rate FTSE, GBP - Swiss Franc FX Rate

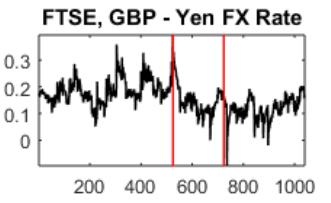

FTSE, Crude Oi
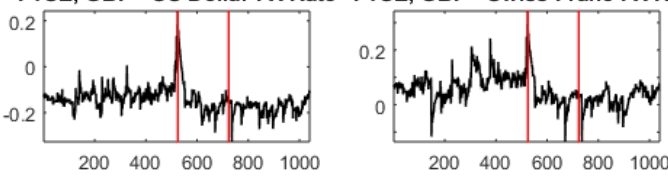

FTSE, Natural Gas
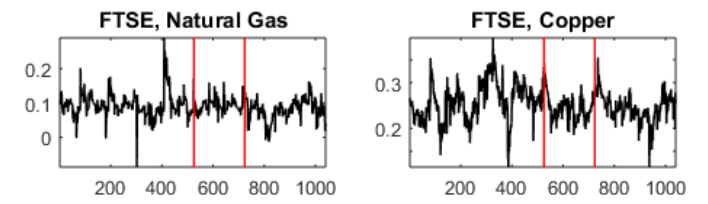

FTSE, Corn
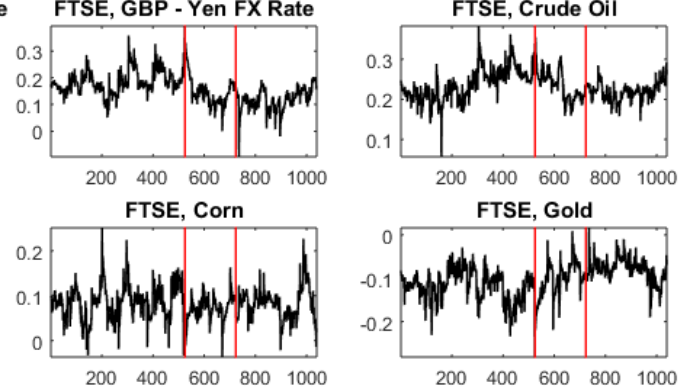

FTSE, Gold
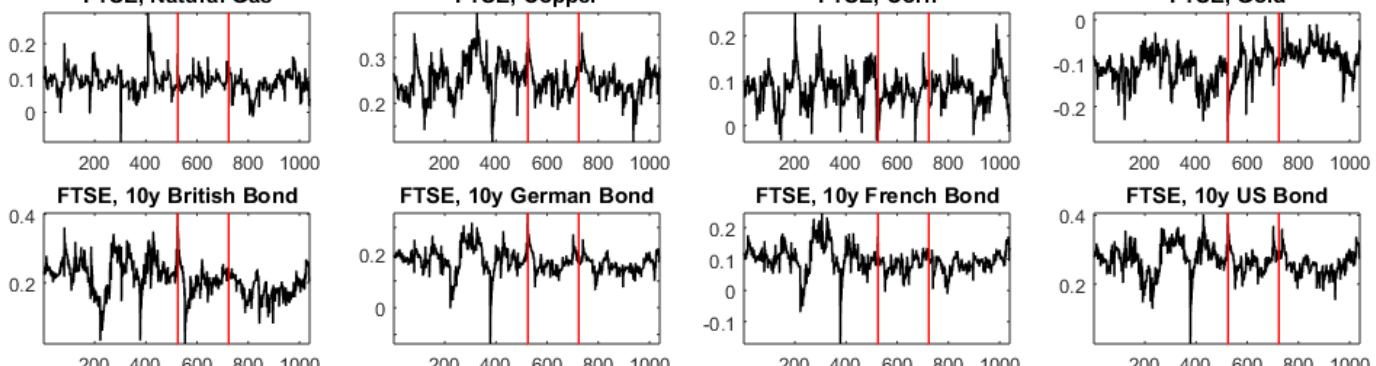

$200 \quad 400 \quad 600 \quad 800 \quad 1000$

$200 \quad 400 \quad 600 \quad 800 \quad 1000$

$200 \quad 400 \quad 600 \quad 800 \quad 1000$

$200 \quad 400 \quad 600 \quad 800 \quad 1000$

Figure 5: Conditional Correlations. First vertical red line is referendum date (June 23, 2016), second red line is date article 50 was triggered (March 29, 2017).
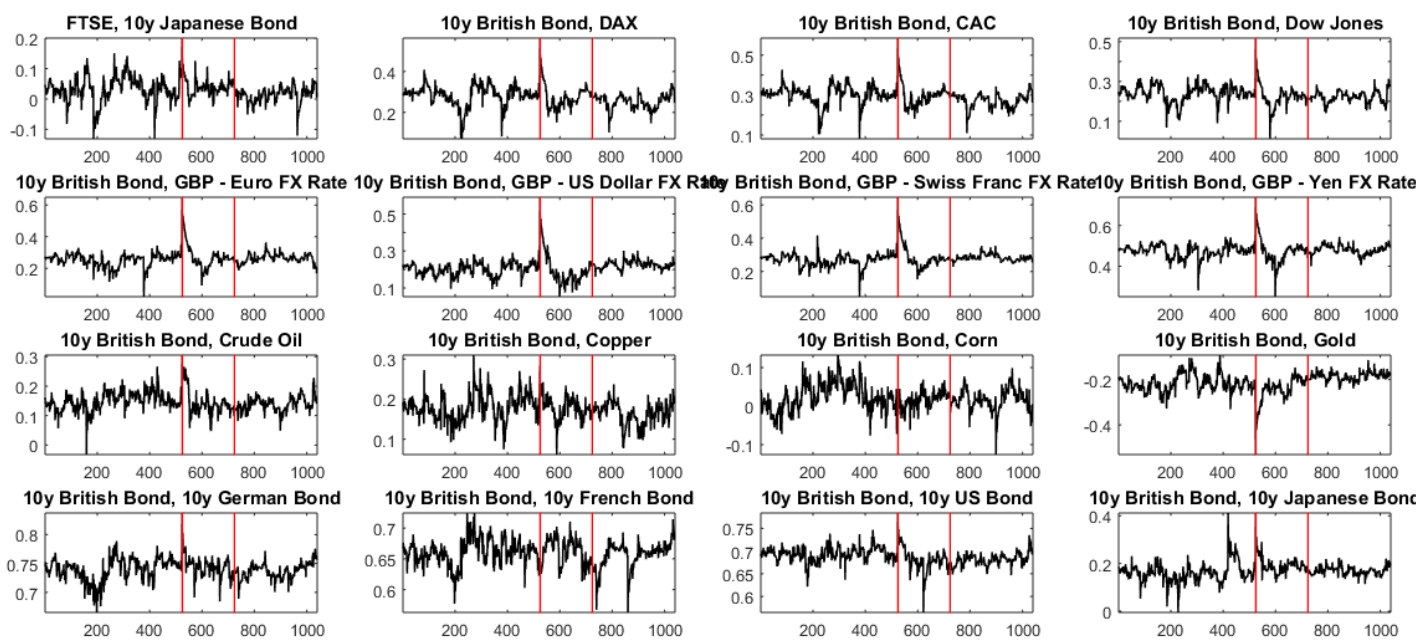

$200 \quad 400 \quad 600 \quad 800 \quad 1000$

$\begin{array}{lllll}200 & 400 & 600 & 800 & 1000\end{array}$

$10 y$ British Bond, 10y Japanese Bon

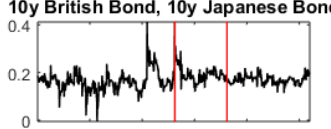

Figure 6: Conditional Correlations. First vertical red line is referendum date, second red line is date article 50 was triggered (March 29, 2017).

In contrast to the conditional variance, we observe a spike on the Brexit referendum day and a structural change (or persistent effects) in various relationships. For example, we find that the conditional correlation between the FTSE and other stock 
market indices and currencies (GBP-Euro, GBP- USD, GBP-CHF, GBP-Yen exchange rates) has decreased considerably after the Brexit referendum day. This change has been permanent. Interestingly, the conditional correlation between the GBP and the USD changed dramatically on Brexit referendum from negative to positive and a couple of weeks later back to (and even more) negative. This indicates a positive comovement of currencies around the Brexit referendum before the adjustments resulted in an even more pronounced negative co-movement with most currencies. For commodities, we find only small changes, which also holds for the conditional correlation of the FTSE with various Treasury bonds.

When we turn to analysing the relationship of the 10 year UK Treasury bonds with the other assets (figure 6), we find that, in contrast to the conditional correlations for the UK stock market, that there is little effect of the Brexit referendum. Again, we observe a spike on the day of the Brexit referendum which quickly reverses, but we do not find permanent effects on the conditional correlations. This is interesting as it suggests that there was no adjustment in the underlying riskiness of the UK government (proxied by the Treasury bond).

We can summarize our findings as follows. The outcome of the Brexit referendum generated a large spike in the riskiness (conditional variance and correlation) of all variables in our sample. While this spike was only temporary (the effects lasted from days to weeks) for the conditional variance, for some conditional correlations of the stock market index it was permanent. We conclude that the Brexit referendum outcome did affect the underling riskiness and the correlation between assets for the stock market, i.e. UK companies, but not for the government (Treasury bonds). We find that this holds for the major trading partners considered: Germany, France, US, 
and Japan. The day article 50 was triggered, as previously argued, had no quantitatively important effect on the conditional correlations.

\section{Conclusion}

This study explores the short-term impact of the Brexit referendum on the comovement of financial asset prices using daily price returns of major stock and bond indices from June 2014 to June 2018. We aim to understand whether the surprising outcome of the Brexit referendum had an effect on the riskiness and the correlation structure of various types of assets.

Several results stand out. First, we document quantitatively relevant changes in the unconditional co-movement of all types of assets. Second, we find that Brexit generated a large spike in the second moments of the variables: conditional variance and correlations reacted strongly to the Brexit referendum outcome. While this spike was only temporary for riskiness, it had persistent effects on the conditional correlation of the British stock market index with other assets. We conclude that the Brexit referendum outcome did affect the underling riskiness and the correlation between assets for the stock market, i.e. UK companies, but not for the government. Our results have implications for risk management, financial stability, and asset pricing models of domestic (Within UK) and international investors and central banks.

Future research should investigate the long-term impact of Brexit on the conditional and unconditional co-movement of UK assets. However, this analysis will suffer from the impacts of the COVID-19-generated recession. 


\section{References}

Andersen T. G., Bollerslev, T., Christoffersen, P., Diebold, F. X., 2007. "Practical Volatility and Correlation Modeling for Financial Market Risk Management." in NBER Chapters: The Risks of Financial Institutions.

Becker, S. O., Fetzer, T., and Novy, D., 2017. Who voted for Brexit? A comprehensive district-level analysis. Economic Policy, 32(92): 601 - 650.

Belke, A. and Ptok, S., 2017. British-European Trade Relations and Brexit: An Empirical Analysis of the Impact of Economic and Financial Uncertainty on Exports. International Journal of Financial Studies, 6(3): 73.

Belke, A., Dubova, I., and Osowski, T., 2018. Policy Uncertainty and International Financial Markets: The Case of Brexit. Applied Economics, 5o: 3752 - 3770.

Branger, N., Muck, M. and Weisheit, S., 2018. Correlation Risk and International Portfolio Choice. Journal of Futures Markets, 39(1): 128 - 146.

Buss, A., Schoenleber, L. and Vilkov, G., 2017.Expected Stock Returns and the Correlation Risk Premium. Mimeo.

Caporale, G. M., Gil-alana, L., and Trani, T., 2018. Brexit and Uncertainty in Financial Markets. International Journal of Financial Studies, 6(1): 21.

Clark, I. J. and Amen, S., 2017. Implied Distributions from GBPUSD Risk-Reversals and Implication for Brexit Scenarios. Risks, 5(3): 35.

Driessen, J., Maenhout, P. J., and Vilkov, G., 2009. The Price of Correlation Risk: Evidence from Equity Options. Journal of Finance, 64(3): 1377 - 1406.

Engle, R. F., 1999. "Dynamic Conditional Correlation - A Simple Class of Multivariate GARCH Models." UCSD Economic Working Papers, 2000-09.

Engle R.F. and Sheppard K., 2001. "Theoretical and Empirical Properties of Dynamic Conditional Correlation Models.” NBER Working Papers, No. 8554.

Embrechts, P., McNeil, A. J., and Straumann, D., 2002. Correlation and Dependence in Risk Management: Properties and Pitfalls. In Dempster, M. A. H., (ed.) "Risk Management: Value at Risk and Beyond.” Cambridge University Press. 
Howartha D. and Quaglia L., 2018. "Brexit and the Battle for Financial Services." Journal of European Public Policy, 25(8), 1118 - 1136.

Jondeau E. and Rockinger M., 2005. "Conditional Asset Allocation under NonNormality: How Costly is the Mean-Variance Criterion." EFA 2005 Moscow Meetings Paper, SSRN No. 674424.

Kara, A., Karimov, N., and Nguyen, A. P., 2020. Brexit referendum and the UK securitization market. Applied Economics Letters, forthcoming.

Kenourgios, D., Dadinakis, E., and Tsakalos, I., 2020. Brexit referendum and European stock markets: a sector analysis. Managerial Finance, forthcoming.

Korniyenko, Y., Patnam, M., del Rio-Chanona, R. M., and Porter, M. A., 2018. Evolution of the Global Financial Network and Contagion: A New Approach. IMF Working Paper, No. 18/113.

Krishnan, C. N. V., Petkova, R., and Ritchken, P., 2009. Correlation Risk. Journal of Empirical Finance, 16(3): 353 - 367.

Li, H., 2020. Volatility spillovers across European stock markets under the uncertainty of Brexit. Economic Modelling, 84: 1-12.

Smales, L. A., 2017. "Brexit”: A Case Study in the Relationship Between Political and Financial Market Uncertainty. International Review of Finance, 17(3): 451-459. 